American Journal of Biochemistry and Biotechnology 6 (3): 155-163, 2010

ISSN 1553-3468

(C) 2010 Science Publications

\title{
The Effect of Citrullus colocynthis Pulp Extract on the Liver of Diabetic Rats a Light and Scanning Electron Microscopic Study
}

\author{
${ }^{1}$ Mohammad Khalil, ${ }^{2}$ Gamal Mohamed, ${ }^{3}$ Mohammad Dallak, ${ }^{3}$ Fahaid Al-Hashem, \\ ${ }^{3}$ Hussein Sakr, ${ }^{4}$ Refaat A. Eid, ${ }^{5}$ Mohamed A. Adly, ${ }^{3}$ Mahmoud Al-Khateeb, \\ ${ }^{7}$ Saleh Banihani, ${ }^{8}$ Zuhair Hassan and ${ }^{8}$ Nabil Bashir \\ ${ }^{1}$ Division of Physiology, Department of Basic Medical Sciences, Faculty of Medicine, \\ King Fahid Medical City, Riyadh 11393, Saudi Arabia \\ ${ }^{2}$ Departments of Anatomy, College of Medicine, Saudi Arabia and Faculty of Medicine, \\ King Khalid University, Abha 64121, Mansoura University, Egypt \\ ${ }^{3}$ Department of Physiology, College of Medicine, King Khalid University, \\ Abha 64121, Saudi Arabia \\ ${ }^{4}$ Department of Pathology, Electron Microscope Unit, College of Medicine, \\ ${ }^{5}$ Division of Histology, Department of Biology, College of Science, \\ King Khalid University, Abha 64121, Saudi Arabia \\ ${ }^{6}$ Division of Biochemistry, Department of Basic Medical Sciences, \\ Faculty of Medicine, King Fahid Medical City, Riyadh 11393, \\ Saudi Arabia and Department of Physiology, Faculty of Medicine, \\ Jordan University of Science and Technology, Irbid 22110, Jordan \\ ${ }^{7}$ Department of Anatomy, \\ ${ }^{8}$ Department of Physiology, \\ Faculty of Medicine, Jordan University of Science and Technology, \\ Irbid 22110, Jordan
}

\begin{abstract}
Problem statement: The goal of the current investigation was to clarify the effects of Citrullus colocynthis pulp extract on the structure of the liver of diabetic rats at both light and scanning electron microscopic levels. Approach: Forty-eight adult male albino rats were equally allocated into four groups: Group1: control, Group 2: Citrullus colocynthis-treated, Group 3: diabetic rats and Group4: diabetic rats treated with Citrullus colocynthis. All treatments were administered via an intragastric tube. Diabetes was induced in the rats of groups 3 and 4 by an intraperitoneal injection with alloxan. Results: The liver of Citrullus colocynthis-treated rats revealed minor histological changes versus the control animals. In group 3 animals, diabetes caused degenerative alterations in the form of disorganization of the hepatic cords, cytoplasmic vacuolization and pyknosis of the nuclei of hepatocytes and inflammatory cell infiltration. Scanning electron microscope examination of these livers revealed numerous lipid droplets within hepatocytes, damaged blood sinusoids and hemorrhage of erythrocytes between hepatocytes and inside Disse's spaces. On the other hand, the normal histological and scanning ultrastructural features were nearly resumed in the liver of diabetic rats treated with Citrullus colocynthis pulp extract. Conclusion: The present study proved a lessening effect of Citrullus colocynthis pulp extract on the liver of diabetic rats. In light of these advantageous influences, it is advisable to widen the scale of its use in a trial to alleviate the diabetic hepatic adverse effects.
\end{abstract}

Key words: Citrullus colocynthis, liver, alloxan, diabetes, rats

\section{INTRODUCTION}

Diabetes mellitus is a chronic metabolic disorder characterized by widespread complications. It is the world's largest endocrine disease associated with increased morbidity and mortality rates (Ghosh and Surawanshi, 2001).

The chronic hyperglycemia of diabetes is associated with long-term damage, dysfunction and failure of various organs (Lyra et al., 2006). Liver

Corresponding Author: Nabil Bashir, Department of Physiology, Faculty of Medicine,

Jordan University of Science and Technology, Irbid 22110, Jordan 
involvement is one of the leading causes of death in diabetes mellitus. The mortality rate from the hepatic affection is greater than that from the cardiovascular complications. The spectrum of liver implication in diabetes ranges from non-alcoholic fatty liver disease to cirrhosis and eventually hepato-cellular carcinoma (Keith et al., 2004). Liver, an insulin-dependent organ, plays a pivotal role in glucose and lipid homeostasis. It participates in the uptake, oxidation and metabolic conversion of free fatty acids and in the synthesis of cholesterol, phospholipids and triglycerides. Several mechanisms are implicated in the pathogenesis of the functional and morphological alterations of the liver of diabetic patients (Brixova, 1981; Moller, 2001).

Experimental diabetes in animals has provided a considerable insight into the physiologic and biochemical derangement of the diabetic state. The alloxan-induced diabetes in rats displays many features seen in human subjects with uncontrolled diabetes. Alloxan is widely employed to evoke diabetes due to the fact that it causes severe necrosis of pancreatic $\beta$ cells with consequent lack of insulin secretion (Szkudelski, 2001). Increased oxidative stress is another possible etiologic mechanism of its diabetogenic action (Halliwell and Gutteridge, 1985).

Plants are reputed in the indigenous systems of medicine for the treatment of various diseases (Arise et al., 2009). Phyto-chemicals isolated from plant sources are used for the prevention and treatment of several medical problems including diabetes mellitus (WaltnerLaw et al., 2002). There are more than 800 plant species showing a hypoglycemic activity. The World Health Organization (1980) has also recommended the evaluation of the effectiveness of plants in conditions where safe modern drugs are lacked.

Citrullus colocynthis (cucurbitaceae), commonly known as "bitter apple", "colosynth", "vine-of-sodom" and "tumba" is a tropical plant that grows abundantly in the Arabian countries and in other parts of the world. In the traditional medicine, this plant has been utilized to treat constipation, diabetes, edema, fever, jaundice, bacterial infections as well as cancer. It is also utilized as an abortifacient (Alkofahi et al., 1996; Ziyyat and Legssyer, 1997; Madari and Jacobs, 2004).

A review of the available literature revealed a lack of the studies pertaining to the histological and ultrastructural effects of Citrullus colocynthis pulp extract on the liver of the diabetic rats. Consequently, the notion of the present investigation arose and was accomplished with an intent to throw light on these effects utilizing both the light and scanning electron microscopes.

\section{MATERIALS AND METHODS}

Preparation of Ciltrullus colocynthis pulp extract: Fresh one kilogram of Citrullus colocynthis fruits was collected from Aseer area, south-western region of Saudi Arabia. Mature black seeds were separated manually from the pulp of the fruits and then the pulps were dried and ground with a grinder (Moulinex, France) into a powder prepared for extraction. The pulp powder was extracted by $1 \mathrm{~L}$ of hydro-ethanol mixture (80/20, v/v) for 6 hours. This step was repeated three times. The filtrate was pooled and concentrated under vacuum at a temperature, not exceeding $50^{\circ} \mathrm{C}$ and dissolved in normal saline (Nmila et al., 2000). The extract was administered at a dose of $1 \mathrm{ml}$ per $\mathrm{kg}$ body weight, equivalent to $300 \mathrm{mg} \mathrm{kg}$. This dose selection was based on our previous studies (Al-Khateeb et al., 2009; Dallak et al., 2009b).

Experimental animals: Adult male albino rats (200$250 \mathrm{~g}$ ) bred in the Central Animal House, Medical College, King Khalid University, were used in this study. They were fed on standard rat chow and water ad libitum. The animals were maintained in their respective groups for 20 days before the beginning of the experimental procedure. They were housed at a controlled ambient temperature of $25 \pm 2^{\circ} \mathrm{C}$ with $50 \pm 10 \%$ relative humidity and with a $12 \mathrm{~h}$ light/12 h dark cycle.

Experimental induction of diabetes: Diabetes was induced in the rats by intra-peritoneal administration of alloxan-monohydrate (purchased from Sigma Chemical Company Inc., St Louis, MO, USA), in a dose of $150 \mathrm{mg} \mathrm{kg}^{-1}$ body weight, dissolved in normal saline. Since this drug is capable of producing initial fatal hypoglycemia as a result of the massive pancreatic insulin release, the animals were treated with $30 \%$ glucose solution orally at different time intervals after $6 \mathrm{~h}$ of alloxan administration and $5 \%$ glucose solution was kept in bottles in their cages for the next $24 \mathrm{~h}$ to prevent this hypoglycemia. After 3 days, successful induction of diabetes was confirmed by the presence of glucose in urine (indicated by Benedict's test) and elevated blood glucose levels to $300-400 \mathrm{mg} \mathrm{dL}^{-1}$ (Alarcon-Aguilar et al., 2000; Evelson et al., 2004).

Experimental design: Forty-eight adult male albino rats were used in the current study. They were equally categorized into four groups, twelve animals in each $(\mathrm{n}=12)$. All treatments were given orally using a modified plastic syringe (intra-gastric tube) at a single 
daily dose $\left(1 \mathrm{~mL} \mathrm{~kg}^{-1}\right)$ for 30 consecutive days as follows:

Group 1: Control rats, given only normal saline Group 2: Citrullus colocynthis-treated rats, in a dose of $300 \mathrm{mg} \mathrm{kg}^{-1}$ day $^{-1}$

Group 3: Diabetic rats, given only normal saline

Group 4: Diabetic rats treated with Citrullus colocynthis as in group 2

At the end of day 30, the animals of all groups were subjected to over-night fasting and then were scarified by cervical dislocation. Following a midline laparotomy, the livers were immediately dissected out, weighed and washed in ice-cold normal saline. The hepatic index for each rat was obtained by dividing its liver weight by the intact rat weight $\times 100 \%$ as described previously by Bujanda et al. (2008). Then, liver tissue samples were immediately processed for light or scanning electron microscopic study.

\section{Histological study:}

Light microscopy: Small pieces of the liver were immersed in 10\% Neutral Buffered Formalin (10\% NBF) solution, dehydrated, cleared and embedded in paraffin. Paraffin sections $(6 \mu \mathrm{m})$ were prepared and stained with Haematoxylin and Eosin (H\&E). The general histological architecture was studied and photographed using the light microscope (Bancroft and Stevens, 1982). Sections were viewed without knowing the group to which each animal belonged. Biopsies were classified into four grades depending on fat accumulation within the hepatocytes using Brunt et al. (1999) classification, assigning grade 0 when no fat was found in the liver; grade1 when fat vacuoles were seen in less than $33 \%$ of hepatocytes; grade 2 when $33-66 \%$ of hepatocytes were affected by these vacuoles and grade 3 when fat vacuoles were detected in more than $66 \%$ of hepatocytes.

Scanning Electron Microscopy (SEM): Fine liver fragments were fixed with $2.5 \%$ (wt/vol) sodium cacodylate-buffered glutaraldehyde, $\mathrm{pH} 7.2$ at $4{ }^{\circ} \mathrm{C}$ for $2 \mathrm{~h}$. Samples were also post-fixed in $1 \%$ sodium cacodylate-buffered osmium tetroxide, $\mathrm{pH} 7.2$ for $1 \mathrm{~h}$. After washing and dehydration in ascending grades of ethanol, critical-point drying was performed using the EMITECH-K850 critical-point drying unit. The samples were mounted on aluminum stubs with doublesided tape and silver glue and then sputter coated with gold by BOC EDWARDS SCANCOAT (Hayat, 1989). The specimens were observed using a Jeol field emission scanning electron microscope JSM-6390LV.
Statistical analysis: The value of the hepatic index of each animal in the four groups was recorded. They were statistically analyzed and expressed as the mean +SD for each group of rats. Standard calculations were performed using SPSS Version 16. Results were subjected to the test for significance and were considered statistically significant at $\mathrm{p} \leq 0.05$ according to Daniel (1987).

\section{RESULTS}

Hepatic index: The mean hepatic index of the control and experimental groups of rats are depicted in Fig. 1. Data shows normal hepatic index in normal rats treated with Citrullus colocynthis as compared to normal rats given normal saline. On the other hand, this hepatic Index was significantly increased in the diabetic rats given normal saline. Diabetic rats treated with Citrullus colocynthis showed a significant decrease in this hepatic index when compared to their control diabetic rats.

Steatosis grades: Table 1 shows fatty infiltration (steatosis) grades in control and experimental groups of rats. Both of normal groups either given normal saline or treated with Citrullus colocynthis extract showed no fatty infiltration and all were of grade 0 , while $75 \%$ of diabetic rats showed sever fatty infiltration of grade 3 , $17 \%$ of grade 2 and $8 \%$ of grade 1 . Treatment of diabetic rats with Citrullus colocynthis hydeo-ethanol extract resulted in $83 \%$ steatosis from grade 1 and $17 \%$ of grade 2 .

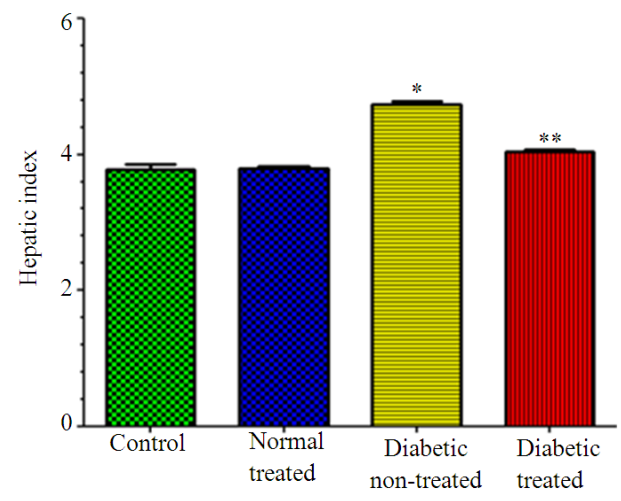

Fig. 1: Hepatic index of control and experimental groups of rats. Values are given as mean \pm SD for groups of 12 rats each. *: Significantly different when compared to normal rats; **: Significantly different when compared to diabetic non treated rats and non significantly different when compared to normal rats. Treated rats when treated with $300 \mathrm{mg} \mathrm{kg} \mathrm{kg}^{-1}$ Citrullus colocynthis hydro-ethanol extract 
Table 1: Grades of fatty infiltration in control and experimental groups of rat

\begin{tabular}{llllll}
\hline & \multicolumn{5}{l}{ Steatosis grade } \\
Group & $\begin{array}{l}\text { Rats } \\
\text { number }\end{array}$ & 0 & 1 & 2 & 3 \\
\hline Control & 12 & 12 & & & \\
Normal + Citrullus colocynthis & 12 & 12 & & & \\
Diabetic non-treated & 12 & & 1 & 2 & 9 \\
Diabetic + Citrullus colocynthis & 12 & & 10 & 2 & 0 \\
\hline
\end{tabular}

Histological features of liver of the Citrullus colocynthis-treated rats: Microscopic examination of the liver of Citrullus colocynthis-treated rats showed minor histological changes versus the control animals. With the light microscope, few hapatocytes had condensed or fragmented nuclei (Fig. 2b). Scanning electron microscopic examination revealed few hepatocytes containing small pores (Fig. $3 \mathrm{c}$ and d).

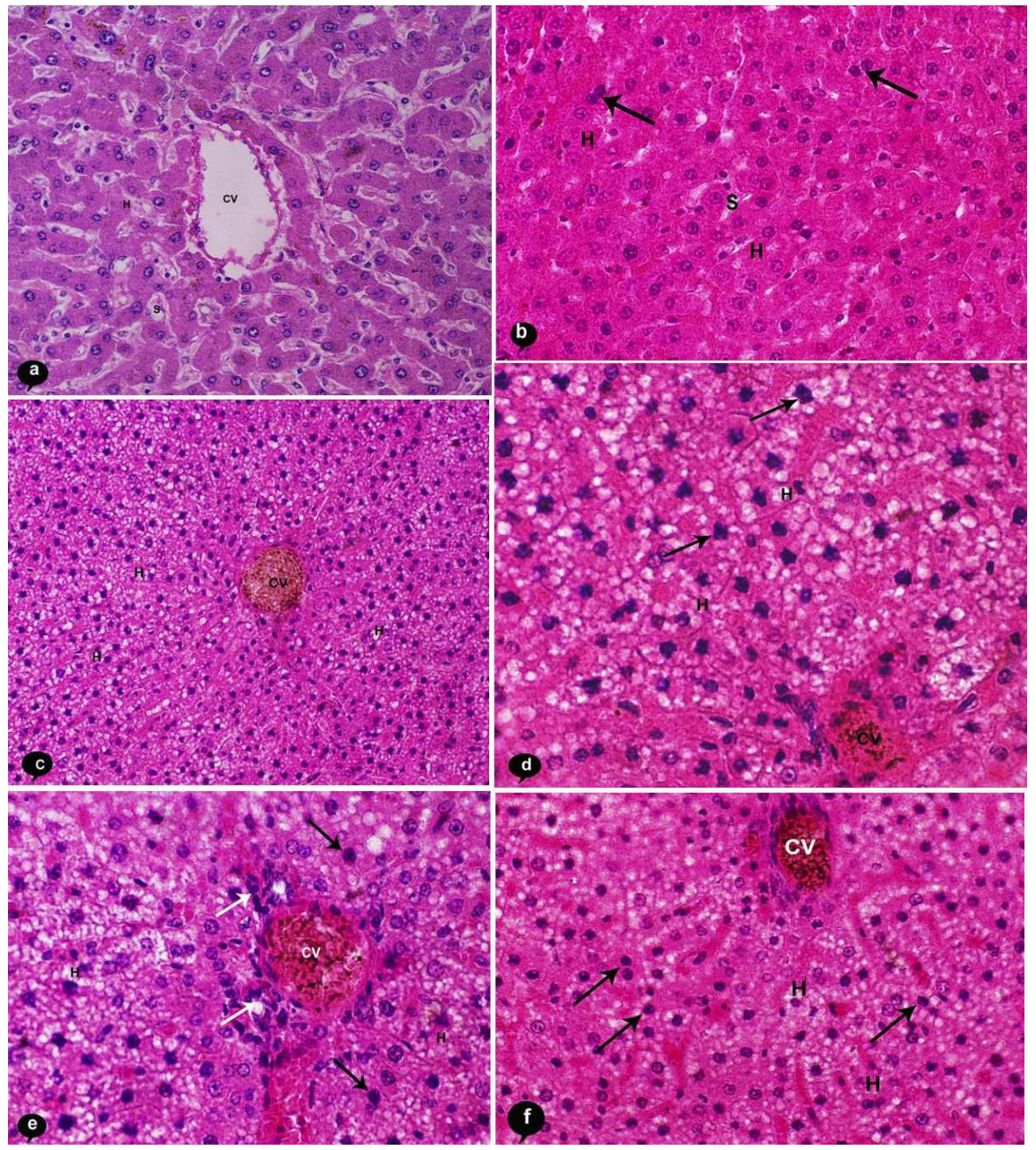

Fig. 2: Photomicrographs of the livers of control, Citrullus colocynthis- treated, diabetic and Citrullus colocynthistreated diabetic rats, H\&E stain; (a) Liver of control rats, $\times 40$; (b) Liver of Citrullus colocynthis treated rats, showing few hapatocytes had condensed or fragmented nuclei $\times 40$; (c) Liver of diabetic rats, showing disorganized hepatic cords, reduced sinusoids and many hepatocytes having cytoplasmic vacuolization, $\times 20$; (d) Higher magnification of (c), showing most hepatocytes with cytoplasmic vacuolar degeneration and pyknotic nuclei (arrows), $\times 40$; (e) Liver diabetic rats, showing a central inflammatory cell infiltration (white arrows) and hepatocytes with cytoplasmic vacuolar degeneration and pyknotic nuclei (black arrows), $\times 40$; (f) Liver of diabetic rats treated with Citrullus colocynthis, showing recovered hepatocytes with less cytoplasmic vacuolization compared with diabetic animals. Few hepatocytes with cytoplasmic vacuolization and pyknotic nuclei are still seen (arrows), $\times 40$ 


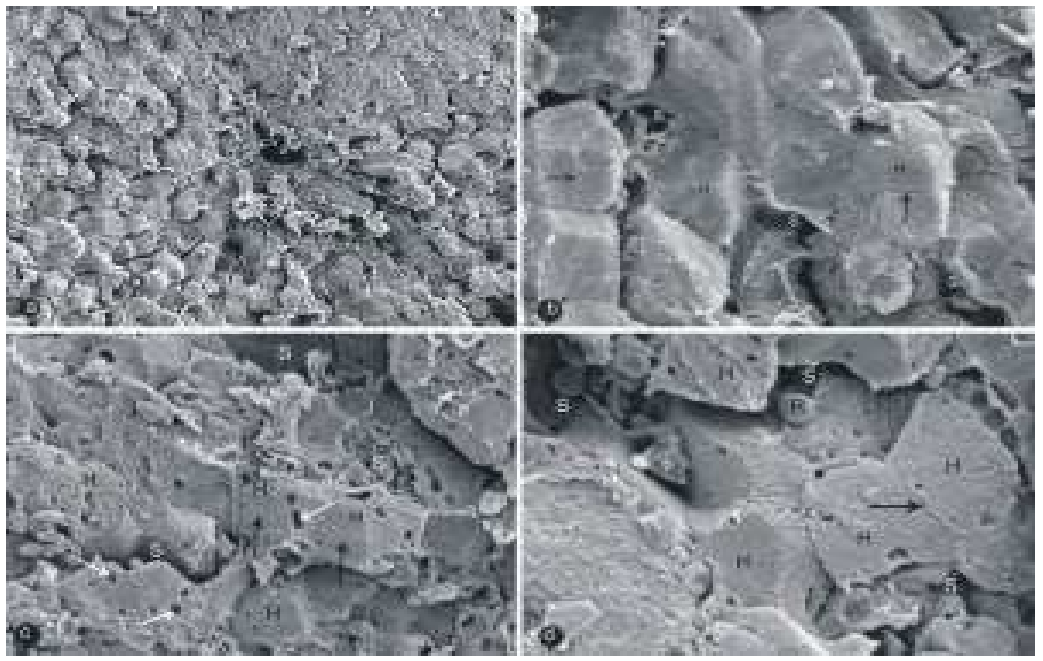

Fig. 3: Scanning electron micrographs of livers of control and Citrullus colocynthis-treated rats. (a) SEM of the liver of control rats showing normal hepatic cord around a Central Vein $(\mathrm{CV}), \times 450$; (b) Larger magnification of (a) showing normal Sinusoids (S) and normal Hepatocytes (H) with normal intercellular boundaries (arrows), $\times 1500$ (c); SEM of the liver of Citrullus colocynthis-treated rats, showing rows of Hepatocytes (H) containing few pores (white arrows). Note the blood Sinusoids (S) and the intercellular boundaries (black arrows), $\times 1100$; (d) Higher magnification of (c), showing blood Sinusoids (S), Hepatocytes (H), intercellular spaces (black arrows) and erythrocytes $(\mathrm{R}), \times 1500$

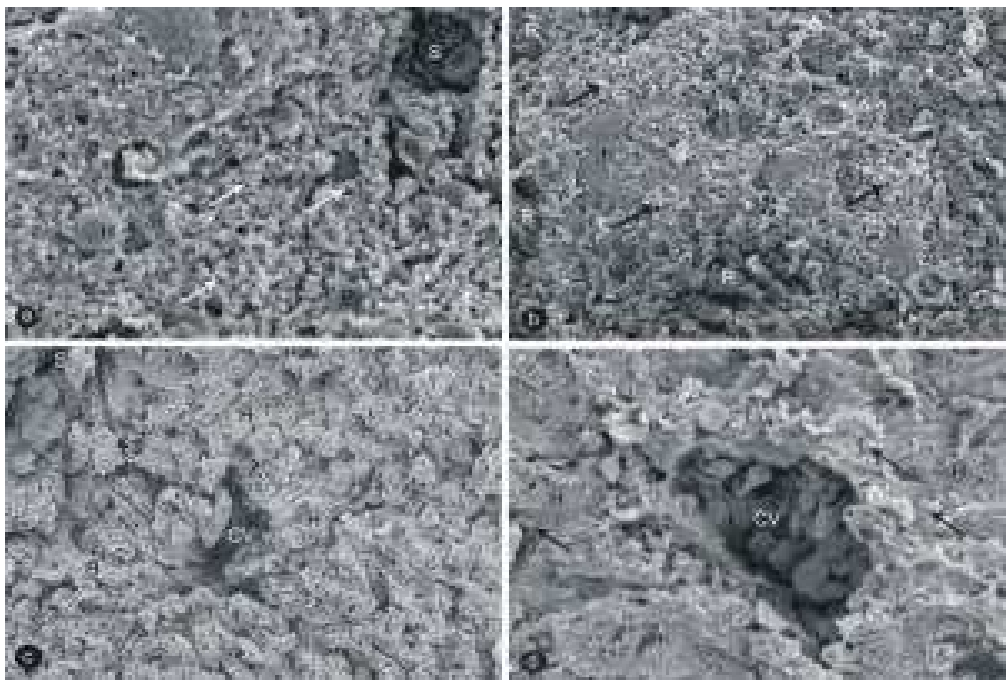

Fig. 4: Scanning electron micrographs of livers of diabetic and Citrullus colocynthis-treated diabetic rats. (a) SEM of the liver of diabetic rats showing degenerating Hepatocytes $(\mathrm{H})$ having a plenty of lipid droplets (white arrows). Damaged blood Sinusoids (S) are also seen as well as some erythrocytes (R) are spread inside hepatocytes, $\times 450$; (b) SEM of the liver of diabetic rats showing hemorrhage of erythrocytes (R) between Hepatocytes (H). Lipid degeneration (black arrows) of hepatocytes is also seen, $\times 450$; (c) SEM of the liver of Citrullus colocynthis-treated diabetic rats, showing intact Hepatocytes $(\mathrm{H})$ and blood Sinusoids (S). Only few hepatocytes around the central vein have some vacuoles, $\times 450$; (d) SEM of the liver of Citrullus colocynthistreated diabetic rats $(300 \mathrm{mg})$ with higher magnification, showing intact Hepatocytes $(\mathrm{H})$ and a Central Vein (CV) containing a lot of erythrocytes. A few hepatocytes around the central vein have a few lipid droplets (arrows), $\times 1100$ 
Histological features of the liver of the diabetic rats: Microscopic examination of the liver of the diabetic rats revealed remarkable changes versus the control rats. These changes included degenerative alterations represented by disorganization of the hepatic cords, cytoplasmic vacuolization and pyknotic nuclei of hepatocytes and inflammatory cell infiltration (Fig. 2ce). Scanning electron microscopic examination showed a plenty of lipid droplets within the hepatocytes. Furthermore, damaged blood sinusoids and hemorrhage of erythrocytes between hepatocytes and inside Disse's spaces were detected (Fig. 4a and b).

Histological features of the liver of the Citrullus colocynthis-treated diabetic rats: Microscopic examination of the liver of diabetic animals treated with Citrullus colocynthis revealed remarkable improvement of hepatic tissue versus the diabetic rats. This was represented by intact blood sinusoids and hepatocytes, except a few hepatocytes around the central vein which still had some cytoplasmic vacuoles Neither erythrocyte hemorrhage nor inflammatory cell infiltration were encountered (Fig. 2f and $4 \mathrm{c}$ and d).

\section{DISCUSSION}

Diabetes mellitus is a group of syndromes characterized by hyperglycemia, altered metabolism of lipids, carbohydrates and proteins, as well as an increased risk of complications from vascular diseases. This clinical question is predicted to increase dramatically in the next few years (Yoshinari et al., 2009). The present study was carried out to evaluate the effects of Citrullus colocynthis pulp extract on the structure of liver of the diabetic rats using the light and scanning electron microscopes.

In the present study, the mean value of the hepatic index showed no significant differences between that of the Citrullus colocynthis-treated and the control rats. On the contrary, there was a significant increase of that index in the diabetic rats compared to the control ones. However, a significant decline in the index of the Citrullus colocynthis-treated diabetic rats in relation to that of the diabetic animals was observed. These findings signify that the Citrullus colocynthis could have no noticeable affection on the liver weight of the normal rats. But, the extract has an obvious significant diminishing effect on the increased hepatic weight already achieved by the diabetic process. This could be attributed to the anti-diabetic influence of that extract on the liver tissue. These findings are in agreement with those postulated by Bujanda et al. (2008). They reported that resveratrol possessed a similar effect on the liver weight and owed this to the inhibitory effect of that polyphenol drug on the non alcoholic fatty liver disease in rats. In the current work, the liver of the diabetic rats showed disorganization of the hepatic cords, vacuolization and pyknotic changes in the nuclei of the hepatocytes. The scanning electron microscopic findings confirmed the degeneration of the hepatocytes with presence of plenty of lipid droplets within these cells. Such alterations could be due to the stress of the diabetic injury and agree with those delivered by several authors. Powell et al. (2005) declared that diabetes is one of the metabolic causes of steatosis (the presence of fat droplets within the hepatocytes). In addition, Kleiner et al. (2005) emphasized that steatosis could take one of two forms either multiple small vesicles (micro-vesicular) or a single large vesicle that may cause ballooning of the hepatocyte (macro-vesicular) so that it resembles a mature adipocyte. The latter form is the predominant one in the non alcoholic fatty liver disease. But mixed forms are not uncommon. Postic and Girard (2008) and Nagle et al. (2009) stated that steatosis is the earliest response and the most common feature of the non alcoholic fatty liver disease. They assumed that the potential sources of this fat include the dietary fatty acids, the increased lipolysis in the white adipose tissue and the newly formed fatty acids within the liver through de novo lipo-genesis.

Following treatment of the diabetic rats with Citrullus colocynthis pulp extract, in the current investigation, their livers showed, more or less, an improvement in the histological architecture with persistence of the cytoplasmic vacuoles in some hepatocytes that could be attributed to the residual adverse effect of the diabetic affliction. But the noticed apparent general improvement signifies that Citrullus colocynthis could possess a cyto-protective abilities on the hepatocytes. The present findings are supported by those announced by Ziyyat and Legssyer (1997) and Aburjai et al. (2007) who confirmed the anti-diabetic properties of Citrullus colocynthis extract. Moreover, Nmila et al. (2000), clarified that different extracts of the seeds of that plant have an insulino-tropic effect evaluated in vitro in the isolated rat pancreas and isolated rat islets in presence of $8.3 \mathrm{M}$ glucose. Also, Sebbagh et al. (2009) stated that this plant could improve the streptozotosin-induced diabetes in rats. Bujanda et al. (2008) owed the similar steatotic inhibitory effect of resveratol to inhibition of the tumor necrosis factor alpha production, lipid per-oxidation 
and oxidative stress. The damaged sinusoids, the haemorrhage and the inflammatory cell infiltration encountered in the liver of the diabetic animals, in this study, might be due to the hyperglycemic state. Seifalian et al. (1999), in an analogous study in rabbits, stressed on that the sinusoidal affection is correlated with the severity of fat accumulation in the parenchymal cells. Moreover, McCuskey et al. (2004) and Kleiner et al. (2005) stressed on that non alcoholic steatosis may be complicated by adhesion of leucocytes to sinusoidal endothelium followed by leucocytic infiltration into the hepatic parenchyma to form inflammatory foci. According to the findings of Khan and Chakarabarti (2003); Hayden et al. (2005) and Ban and Twigg (2008), hyperglycemia is the main offending factor in the onset of the micro-vascular diabetic complications. Fortunately, following Citrullus colocynthis intake, in our study, the damaged sinusoids, the haemorrhage and the inflammatory cell infiltration subsided indicating a beneficial role of such a remedy. These findings are supported by those claimed by Alarcon-Aguilar et al. (2000). Despite the obvious antidiabetic effect of Citrullus colocynthis pulp extract, its use in normal rats, in the current work, caused hepatocytic poration and few hapatocytes had condensed or fragmented nuclei indicating minimal hepatotoxicity. These findings are supported by previous clinical observations in rats and sheep in the form of diarrhea, ruffled hair and decreased body weight (Al-Yahya et al., 2000; Adam et al., 2001; Dehghani and Pajehshahin, 2006). These minimal drawbacks could be combated by further purification techniques.

\section{CONCLUSION}

In conclusion, in light of the beneficial hepatoprotective effects of Citrullus colocynthis bulb extract detected in the current investigation, it is advisable to widen the scale of its use, after further purification procedures, for patients at high risk of diabetes mellitus in a trial to alleviate the diabetic undesirable hepatic hazards.

\section{ACKNOWLEDGMENT}

The researchers would like to thank the deanships of research in Jordan University of Science and Technology and King Khalid University, Abha 64121, Saudi Arabia.

\section{REFERENCES}

Aburjai, T., M. Hudaib, R. Tayyem, M. Yousef and M. Qishawi, 2007. Ethno-pharmacological survey of medicinal herbs in Jordan, the Ajloun heights region. J. Ethnopharmacol., 110: 294-304. PMID: 17097250

Adam, S.E., M.A. Al-Yahya and A.H. Al-Farhan, 2001. Response of Najdi sheep to oral administration of Citrullus colocynthis fruits, nerium olcander leaves or their mixtures. Small Rum Res., 40: 239-244. PMID: 11323208

Alarcon-Aguilar, F.J., M. Jimenez-Estrad, R. ReyesChilpa and R. Roman-Ramos, 2000. Hypoglycemic effect of extracts and fractions from Psacalium decompositum in healthy and alloxan-diabetic mice. J. Ethnopharmacol., 72: 21-27. PMID: 10967449

Alkofahi, A., R. Batshoun, W. Owis and N. Najib, 1996. Biological activity of some Jordanian medicinal plants extracts. Fitoterapia, 67: 435-442. http://cat.inist.fr/?aModele $=$ afficheN\&cpsidt $=2522$ 044

Al-Khateeb, M., M. Dallak, F. Al-Hashem, N. Bashir and M. Abbas et al., 2009. In vivo, acute, normohypoglycemic, antihyperglycemic actions of orally administered ethanol extract of Citrullus colocynthis (L.) schrab pulp. Am. J. Biochem. Biotechnol., 5: 118-125.

http://www.scipub.org/fulltext/ajbb/ajbb53118-125.pdf

Al-Yahya, M.A., A.H. Al-Farhan and S.E. Adam, 2000. Preliminary toxicity study on the individual and combined effects of Citrullus colocynthis and nerium onlander in rats. Fitoterapia, 71: 385-391. DOI: $10.1016 / \mathrm{S} 0367-326 \mathrm{X}(00) 00135-0$

Arise, R.O., S.O. Malomo, J.O. Adebayo and A. Igunnu, 2009. Effects of aqueous extract of eucalyptus globules on lipid peroxidation and selected enzymes of rat liver. J. Med. Plants Res., 3: 77-81. http://www.unilorin.edu.ng/publications/igunnu/Ig unnu\%202.pdf

Ban, C.R. and S.M. Twigg, 2008. Fibrosis in diabetes complications: Pathogenic mechanisms and circulating and urinary markers. Vasc. Health Risk Manage., 4: 575-596. PMID: 18827908

Bancroft, J.D. and A. Stevens, 1982. Theory and Practice of Histology Techniques. 2nd Edn., Churchill Livingstone, Edenburgh, London, Melbourne and New York, pp: 680.

Brixova, E., 1981. Experimental and clinical liver steatosis. Folia Fac. Med. Univ. Comenian Bratisl., 19: 9-90. 
Brunt, E.M., C.G. Janney, A.M. di Bisceglie, B.A. Neuschwander-Tetri and B.R. Bacon, 1999. Non-alcoholic steato-hepatitis: A proposal for grading and staging the histological lesions. Am. J. Gastroenterol., 94: 2467-2474. PMID: 10484010

Bujanda, L., E. Hijono, M. Larzabal, M. Beraza and P. Aldazabal et al., 2008. Resveratrol inhibits non-alcoholic fatty liver disease in rats. BMC Gastroenterol., 8: 40-40. DOI: 10.1186/1471-230X-8-40

Dallak, M., N. Bashir, M. Abbas, R. Elessa and M. Haidara et al., 2009. Concomitant down regulation of glycolytic enzymes, upregulation of gluconeogenic enzymes and potential hepatonephro-protective effects following the chronic administration of the hypoglycemic, insulinotropic Citrullus colocynthis pulp extract. Am. J. Biochem. Biotechnol., 5: 153-161. http://www.scipub.org/fulltext/ajbb/ajbb54153-161.pdf

Daniel, W.W., 1987. Biostatistics: A Foundation for Analysis in the Health Sciences. 4th Edn., Wiley, USA., ISBN: 0471852643, pp: 734.

Dehghani, F. and M.R. Pajehshahin, 2006. The toxic effect of alcoholic extract of Citrullus colocynthis on rat liver. Iran. J. Pharmacol. Therapeut., 5: 117-119. http://www.bioline.org.br/pdf?pt06019

Evelson, P., S. Liesuy, E. Filinger, R.R. Rodriguez and A. Lemberg et al., 2004. Decreased oxidative stress in prehepatic portal hypertensive in rat livers following the induction of diabetes. Clin. Exp. Pharmacol. Physiol., 31: 169-173. DOI: 10.1111/j.1440-1681.2004.03963.x

Ghosh, S. and S.A. Surawanshi, 2001. Effect of Vinca rosea extracts in treatment of alloxan diabetes in male albino rats. Indian J. Exp. Biol., 39: 748-759. PMID: 12018575

Halliwell, B. and J.M.C. Gutteridge, 1985. Free Radicals in Biology and Medicine. 1st Edn., Oxford University Press, USA., pp: 280.

Hayat, M.A., 1989. Principles and Techniques of Electron Microscopy Biological Application. 3rd Edn., CRC Press, Boca Raton, FL., pp: 469.

Hayden, M.R., J.R. Sowers and S.C. Tyagi, 2005. The central role of vascular extracellular matrix and basement membrane remodeling in metabolic syndrome in type and 2 diabetes: The matrix preloaded. Cardiovasc. Diabetol., 4: 9-9. DOI: 10.1186/1475-2840-4-9

Keith, K.G., V. Fonseca, M.H. Tan and A. Dalpiaz, 2004. Narrative review: Hepatobiliary disease in type 2 diabetes mellitus. Ann. Intern. Med., 141: 946-956. PMID: 15611492

Khan, Z.A. and S. Chakarabarti, 2003. Endothelins in chronic diabetic complications. Can. J. Physiol. Pharmol., 81: 622-634. DOI: 10.1139/Y03-053
Kleiner, D.E., E.M. Brunt, M. van Natta, C. Behling and M.J. Contos et al., 2005. Design and validation of a histological scoring system for nonalcoholic fatty liver disease. Hepatology, 41: 1313-1321. PMID: 15915461

Lyra, R., M. Oliveira, D. Lins and N. Cavalcanti, 2006. Prevention of type 2 diabetes mellitus. Arq Bras Endocrinol. Metabol., 50: 239-249.

Madari, H. and R.S. Jacobs, 2004. An analysis of cytotoxic botanical formulations used in the traditional medicine of ancient Persia as abortifacients. J. Nat. Prod., 67: 1204-1210. DOI: 10.1021/np049953r

McCuskey, R.S., Y. Ito, G.R. Robertson, M. Perry and G.C. Farrell, 2004. Hepatic micro-vascular dysfunction during evolution of dietary steatohepatitis in mice. Hepatology, 40: 386-393. PMID: 15368443

Moller, D.E., 2001. New drug targets for type 2 diabetes and the metabolic syndrome. Nature, 414: 821-827. PMID: 11742415

Nagle, C.A., E.L. Klett and R.A. Coleman, 2009. Hepatic triacylglycerol accumulation and insulin resistance. J Lipid Res., 50: 74-79. PMID: 18997164

Nmila, R., R. Gross, H. Rchid, M. Roye and M. Manteghetti et al., 2000. Insulinotropic effect of Citrullus colocynthis fruit extracts. Planta Med., 66: 418-423. PMID: 10909260

Postic, C. and J. Girard, 2008. The role of lipogenic pathway in the development of hepatic steatosis. Diabetes Metab., 34: 643-648. PMID: 19195625

Powell, E.E., J.R. Jonsson and A.D. Clouston, 2005. Steatosis: Co-factor in other liver diseases. Hepatology, 42: 5-13. PMID: 20222159

Sebbagh, N., C. Cruciani-Guglielmacci, F. Cruciani, Guglielmacci, M.F. Berthault and C. Rouch et al., 2009. Comparative effects of Citrullus colocynthis, sunflower and olive oil-enriched diet on streptozotocin-induced diabetes in rats. Diabetes Metab., 35: 178-184. PMID: 19264524

Seifalian, A.M., C. Piasecki, A. Agawel and B.R. Davidson, 1999. The effect of graded steatosis on flow in the hepatic on flow in the hepatic parenchymal microcirculation. Transplantation, 68: 780-784. PMID: 10515377

Szkudelski, T., 2001. The mechanism of alloxan and streptozotocin action in B cells of the rat pancreas. Physiol. Res., 50: 537-546. PMID: 11829314

Waltner-Law, M.E., X.L. Wang, B.K. Law, R.K. Hall and M. Nawano et al., 2002. Epigallocatechin gallate, a constituent of green tea, represses hepatic glucose production. J. Biol. Chem., 277: 34933-34940. PMID: 12118006 
World Health Organization, 1980. WHO expert committee on diabetes mellitus. WHO. http://whqlibdoc.who.int/trs/WHO_TRS_646.pdf

Yoshinari, O., H. Sato and K. Igarashi, 2009. Antidiabetic effect of pumpkin and its components, trigonielline and nicotinic acid, on goto-kakizaki rats. Biosci. Biotechnol. Biochem., 73: 1033-1041. PMID: 19420712
Ziyyat, A., A. Legssyer, H. Mekhfi, A. Dassouli and M. Serhrouchni et al., 1997. Phyto-therapy of hypertension and diabetes in oriental Morocco. J. Ethnopharmacol., 58: 45-54. DOI: 10.1016/S03788741(97)00077-9 